\title{
Letter to Editor: Role of an orthogeriatrician in the management of patients with hip fracture
}

\author{
Cristian Aletto ${ }^{1,2} \cdot$ Rocco Aicale $^{1,2} \cdot$ Nicola Maffulli ${ }^{1,2,3,4}$
}

Received: 4 July 2021 / Accepted: 6 July 2021 / Published online: 29 July 2021

(c) SICOT aisbl 2021

\section{Dear Dr. Scarlat}

We have read with great interest the article by Dr. Marcheix et al. on the impact of an orthogeratrician on the management of patients with hip fractures [1]. It is refreshing to note how several groups in different countries are undertaking work on such important aspect of the management of these patients. We recently published our own experience in this field [2]. We collected data of 352 patients and divided them in two groups. In the year when the orthogeriatrician started to work in our Orthopaedic Department, our colleague led a multidisciplinary team to manage elderly patients with hip fractures, ensuring that the time to surgery from admission was less than 48 hours. In addition, the hospitalization time after surgery decreased from a mean of $10.1 \pm 4.5 \mathrm{SD}$ to $8.7 \pm 3.2 \mathrm{SD}$, and the total length of stay was statistically reduced from a mean of 12.2 days $\pm 5 \mathrm{SD}$ to 10.8 days $\pm 3.7 \mathrm{SD}$. Given these data, the employment of a geriatrician in the Orthopaedic Department makes sense from a medical and a health economics perspective.

Cristian Aletto

cris.aletto28@gmail.com

$\triangle$ Rocco Aicale aicale17@gmail.com

$\triangle$ Nicola Maffulli n.maffulli@qmul.ac.uk

1 Department of Musculoskeletal Disorders, Faculty of Medicine and Surgery, University of Salerno, 84084 Baronissi, Italy

2 Clinica Ortopedica, Ospedale San Giovanni Di Dio E Ruggi D’Aragona, 84131 Salerno, Italy

3 Barts and the London School of Medicine and Dentistry, Centre for Sports and Exercise Medicine, Mile End Hospital, Queen Mary University of London, 275 Bancroft Road, London E1 4DG, England

4 Faculty of Medicine, School of Pharmacy and Bioengineering, Guy Hilton Research Centre, Keele University, Thornburrow Drive, Hartshill, Stoke-on-Trent ST4 7QB, England

\section{Declarations}

Conflict of interest The authors declare no competing interests.

\section{References}

1. Marcheix P-S, Collin C, Hardy J et al (2021) Impact of orthogeriatric management on the average length of stay of patients aged over seventy five years admitted to hospital after hip fractures. Int Orthop 45:1431-1438. https://doi.org/10.1007/ s00264-020-04908-z

2. Aletto C, Aicale R, Pezzuti G et al (2020) Impact of an orthogeriatrician on length of stay of elderly patient with hip fracture. Osteoporos Int 31:2161-2166. https://doi.org/10.1007/ s00198-020-05510-0

Publisher's note Springer Nature remains neutral with regard to jurisdictional claims in published maps and institutional affiliations. 